\title{
ERRATUM
}

\section{Erratum to "Thermal Conductivity of Oxide Scale Thermally Grown on Iron Substrate Corrected by Temperature-dependent Interfacial Thermal Resistance in Laser Flash Measurement" [ISIJ International, 59 (2019), No. 3, pp. 398-403]}

Mu LI, ${ }^{1,2)}$ Rie ENDO, ${ }^{3)}$ Megumi AKOSHIMA, ${ }^{2)}$ Hiroshi TANEI, ${ }^{4)}$ Hikaru OKADA ${ }^{5)}$ and Masahiro SUSA ${ }^{3)}$

1) Department of Metallurgy and Ceramics Science, Tokyo Institute of Technology, Ookayama, Meguro-Ku, Tokyo, 1528552 Japan.

2) Research Institute for Material and Chemical Measurement, National Institute of Advanced Industry Science and Technology, Tsukuba, Ibaraki, 305-8586 Japan.

3) Department of Materials Science and Engineering, Tokyo Institute of Technology, Ookayama, Meguro-Ku, Tokyo, 152-8552 Japan.

4) Process Research Laboratories, Nippon Steel \& Sumitomo Metal Corporation, 20-1 Shintomi, Futtsu, Chiba, $293-8511$ Japan.

5) Kashima R\&D Laboratories, Nippon Steel \& Sumitomo Metal Corporation, 3 Hikari, Kashima, Ibaraki, $314-0014$ Japan.

DOI: https://dx.doi.org/10.2355/isijinternational.ISIJINT-2018-553

The authors have made a mistake in description of Eq. (2) in ISIJ Int., 59 (2019), No. 3, pp. 398-403. The authors are extremely regretful for the carelessness, and we would like to correct the equation as follows:

Error:

$$
\tau_{\mathrm{A}-\text { meas }}=\frac{\tau\left(2 C_{\mathrm{A}}+C_{\mathrm{B}}\right)-6 \tau_{\mathrm{B}}\left(2 C_{\mathrm{A}}+C_{\mathrm{B}} / 6+C_{\mathrm{A}}^{2} / C_{\mathrm{B}}\right)}{6 C_{\mathrm{B}}+8 C_{\mathrm{A}}}
$$

Correct:

$$
\tau_{\mathrm{A}-\text { meas }}=\frac{\tau\left(2 C_{\mathrm{A}}+C_{\mathrm{B}}\right)-6 \tau_{\mathrm{B}}\left(C_{\mathrm{A}}+C_{\mathrm{B}} / 6+C_{\mathrm{A}}^{2} / C_{\mathrm{B}}\right)}{6 C_{\mathrm{B}}+8 C_{\mathrm{A}}}
$$

The same mistake was made in Eq. (4) in ISIJ Int., 57 (2017), No. 12, pp. 2097-2106 as well.

Error:

$$
\tau_{\text {scale }}=\frac{3 A_{\mathrm{d}}\left(2 C_{\mathrm{FeO}}+C_{\mathrm{Fe}}\right)-3 \tau_{\mathrm{Fe}}\left(2 C_{\mathrm{FeO}}+C_{\mathrm{Fe}} / 6+C_{\mathrm{FeO}}^{2} / C_{\mathrm{Fe}}\right)}{3 C_{\mathrm{Fe}}+4 C_{\mathrm{FeO}}}
$$

Correct:

$$
\tau_{\text {scale }}=\frac{3 A_{\mathrm{d}}\left(2 C_{\mathrm{FeO}}+C_{\mathrm{Fe}}\right)-3 \tau_{\mathrm{Fe}}\left(C_{\mathrm{FeO}}+C_{\mathrm{Fe}} / 6+C_{\mathrm{FeO}}^{2} / C_{\mathrm{Fe}}\right)}{3 C_{\mathrm{Fe}}+4 C_{\mathrm{FeO}}}
$$

However, the authors have confirmed that calculation was made correctly, and thus there are no changes in the calculated results in each case.

The authors apologize for any inconvenience caused by this mistake. 